\title{
An Assessment of Disproportionate Minority \\ Confinement: Evidence from Juvenile Justice and Delinquency Prevention Act
}

\author{
Julian L. Scott III \\ Prairie View A\&M University, Texas A\&M University System \\ Email: jlscott@pvamu.edu \\ G. Solomon Osho \\ Prairie View A\&M University, Texas A\&M University System \\ Email: gsosho@pvamu.edu
}

Doi:10.5296/jsr.v6i1.6328ＵRL: http://dx.doi.org/10.5296/jsr.v6i1.6328

\begin{abstract}
Disproportionate Minority Confinement (DMC) has made some states' reexamine their policies to reduce the number of minorities that are processed into the criminal justice system. "In 1998, Congress amended the Juvenile Justice and Delinquency Prevention Act by requiring that states receiving funding from Title II Part B Formula Grants program to address the issue of disproportionate minority confinement"(Rodney and Tachia, 2004.) Has the amending of Title II part B brought a trend to reduce the number of disproportionate minorities confined to secure facilities? Have other factors involved with the arrest, processing, and confinement of minorities contradict the role in which Title II Part B was intended.
\end{abstract}

Keywords: Disproportionate Minority Confinement, Delinquency, Overrepresentation

\section{Introduction}

Under the "disproportionate minority confinement" requirement in the Juvenile Justice and Delinquency Prevention Act, States must determine whether the proportion of minorities exceeds their proportion in the population. If such overrepresentation is found, states must demonstrate efforts to reduce it (Bilchik 1999). "The most difficult issue in determining which populations is categorically overrepresented lie within the meaning of overrepresentation, disparity, and discrimination. Overrepresentation refers to a situation in which the larger population of a particular group is present at various stages within the juvenile justice system (intake, detention, adjudication, and disposition) that would be expected based on their proportion in the general population. Disparity means that the probability of receiving a particular outcome differs for different groups may in turn lead to overrepresentation. Discrimination occurs if and when the juvenile justice system treats one 
group of juveniles based wholly, or in part, on their gender, racial, and ethnic status (Bilchick, 1999). In, Texas "the problem of minority overrepresentation was first investigated in 1990 in response to the federal government requirement that each state receiving funds from the Juvenile Justice and Delinquency Act determine the existence of this problem and propose ways to rectify minority overrepresentation" (Rodney and Tachia, 2004). Most importantly noted by Rodney and Tachia (2004) in the examination of three rural Texas counties are the changing demographics of the state becoming a minority majority state therefore "if the problem is not seriously addressed the majority of the youth population of the state will be in the juvenile justice system (Rodney and Tachia, 2004).

\section{Prior Studies}

Pope et. al (2001) identified the five phases involved with efforts to reduce the number of minorities impacted by disproportionate minority confinement. The five phases that address the problem of disproportionate confinement are: 1). Identifying the extent to which DMC exist; 2). Assessing the reason for DMC if it exists; 3). Developing an intervention plan to address the identified reasons; 4). Evaluating the effectiveness of strategies to address DMC; 5). Monitoring DMC trends over time. Bilchik (1999) reveals "disproportionate minority confinement sends a signal that we need to take a closer look at how our society treats minority children). Lotke and Schiraldi (2005) examined two specific models in Portland, Oregon and Santa Cruz, California to compare two distinct cities and their attempts to reduce the number of minorities confined in facilities. The research was intended to if the leadership in the cities had a basic plan for reducing the number of minority youths' confined within their facilities. Santa Cruz and Multomah counties developed a plan that began with identifying problems in leadership, collaboration with community leaders and criminal justice system professionals, relevant data collection, objectivity in decision making, cultural competence, partnership with families, alternative to formal handling and incarceration, treatment continuums, and failures (recidivism). Scott McDonald, Director of Juvenile Probation in Santa Cruz, explains, "We stopped trying to look at what was wrong with the kids and trying to fix them. Instead, we looked at ourselves and tried to fix the system. The result was better use of resources, better behavior by the kids, and the reductions in racial and ethnic disparities (Lotke and Schiraldi, 2005).

The Santa Cruz and Multomah county juvenile justice agencies are directing efforts to improve policies to reduce DMC research findings have been mixed, delaying the implementation of effective policies to reduce overrepresentation (Engen, Steen, and Bridges, 2002). According to Bishop and Frazier (1988), extensive research has been performed to examine the relationship between race and decision making in the criminal justice system but drawing firm conclusions are difficult. Racial minorities are oftentimes the victims of severe sentencing. Dahrendorf (1958), presented a pluralistic version of conflict in society in which he showed two faces of society both consensus and conflict, existing in a dialectical relationship (Balkan et. al. 1980, 336). Dahrendorf consider conflict not as a matter of a particular underlying inequality of economic interests but can be based on any difference. 


\section{Al Macrothink}

Journal of Sociological Research

ISSN 1948-5468

2015, Vol. 6, No.1

The four most common explanations for racial disparities in the juvenile justice systems are: 1). the differential involvement thesis; 2). the differential treatment/ discrimination thesis; 3 ). structural processual explanation; and 4). macro- contextual explanation. Of the four common explanations for racial disparities in the juvenile justice system the structural processual argument stress the effects of status characteristics and how it will vary across stages of the juvenile justice process (Engen, Steen, and Bridges 2002). According to Engen, Steen, and Bridges (2002) structural processual explanations impact methodology on racial disparity greatly. "First, decisions made at earlier stages in the process affect decisions made at later stages in the process may reappear as discrimination in later stages (pg.198). Consequently, analysis that do not control for earlier should be less likely to detect race effects than those that do not. Similarly, dispositions made on previous court referrals may affect subsequent dispositions.

In Texas, an analysis by the states correction facilities found that $80 \%$ of the youth's committed to its care were African American and Hispanic (Rodney and Tachia, 2004). Tachia and Rodneys' (2004) analysis examined the problem by looking at the youth's family, social background and prior involvement in delinquency. Specific research questions that were analyzed were: 1). Are specific ethnic minorities over represented in the juvenile justice systems in a rural southwest state. A common explanation for minority over representation is minorities are committing more crime (Rodney, Tachia, and Walters, 2004). Importantly however, no studies have been performed to examine the problem of minority representation in the rural southwestern states.

Sorenson, Hope, and Stemen (2003) examined race specific measures to explain the unexplained racial proportionality in incarceration rates across regions for an explanation of racial disproportionality in incarceration rates. Clarification of the offender, the offender's circumstances, and elements of the case interact to influence certain outcomes (Bridges, Engen, and Steen, 2002, pg.196). Leiber and Stairs (1992) addressed the extent to which social context influence outcome decisions for African American youth compared to their white counterparts. Age, race, sex, and severity are significant determinants in sentencing youths to juvenile confinement or adult transfer to adult court.

\section{Methods}

The data set used for the study was obtained from the Texas Juvenile Crime Prevention Center at Prairie View A\&M University located in Prairie View, Texas. The data extrapolated from the larger data set contained 11,059 cases of juveniles, ages 10-17 to determine whether factors such as age, sex, and race are used to determine sentencing outcomes for the year 2001. 
Table 1. Descriptive Statistics

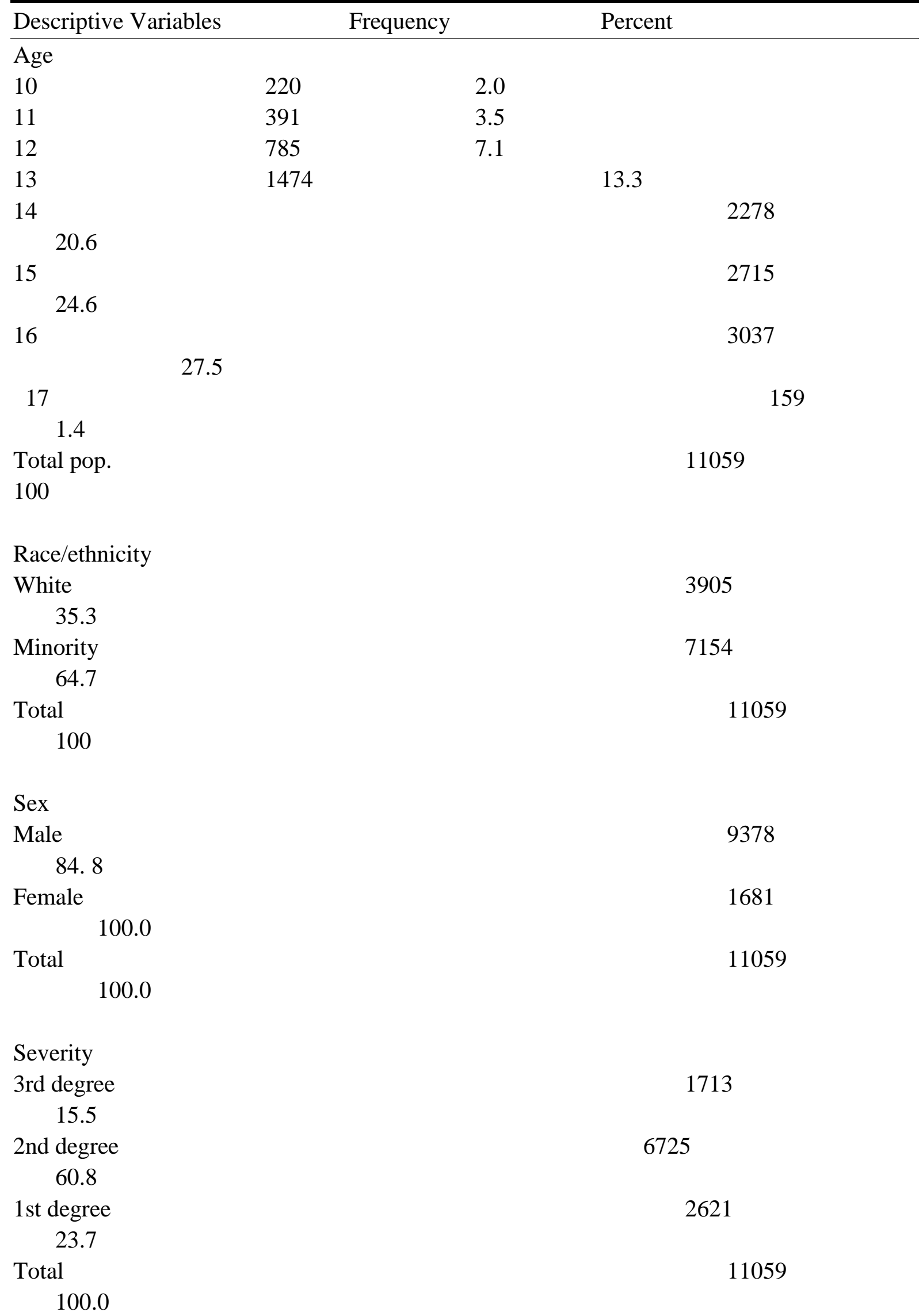


TYC/Adult

.00

10195

92.2

1.00

864

100.0

Total

11059

100.0

Table 1 reveals the valid percentages of youth's age, race and ethnicity, sex, and TYC or adults. Youths ages 10-17 $(n=11059)$ were extrapolated from a larger data set. The age groups 14- 16 have the highest number of cases as compared to youths ages 10-12 (i.e. $10=220 ; 11=391 ; 12=785$ ). Within the age groups $14-16$, the valid percentages are relatively close yet youths within that specific group yield the highest number of youths within the study (i.e. $14=20.6 \% ; 15=24.6 \%$; and $16=27.5 \%$ ). however youths age 16 are shown to have the most individuals within the data set than those of other ages. One can infer youth's ages 14-16 are processed more often than youths 10-12 and 17. Minority youths as compared to white youths are more likely to be processed by the courts; this ultimately determines the type of disposition that one would receive. Minority youths have a total of 7154 within the data set as compared to 3905 whites. Minority youths $(64.7 \%)$ are two times likely to be processed and sent to TYC or adult court than white youths (35.3\%). It is reveals both the age groups and racial composition of youths affected by disproportionate confinement. Relative to the factors pertaining to race and age are the sex and type of offense committed. Tables also will examine additional independent variables as sex and type of offense to provide an overview. According to the table mentioned males are the majority $(84.8 \%)$ whereas females are comprised of $15.2 \%$ of youths that commit offenses.

According to the figures one can conclude that males are nearly four times more likely to commit deviant behaviors than females. Since the felonies were recoded the study will not provide the specific felony however, felonies were categorized by the degree. Severity of the offenses committed by 11059 youths was also examined but severity was recoded, due to gaps in the larger data set. Felonies instead of misdemeanors were examined; 60.8 percent of the youths examine committed second degree felonies. First degree felonies were committed by 23.7 percent of youths and 15.5 percent of youths committed second degree felonies. Table 1 gave a description of the frequencies of the independent variables age, race/ethnicity, sex, and severity as to how each relates to the dependent variable TYC or jail.

Table 2 will provide the figures that pertain only to the frequencies related to the dependent variable. The figures below show that of the 11059 cases 10195 (92.2\%) of those examined were sentenced to confinement to TYC. $864(7.8 . \%)$ of the cases were transferred to adult court. The frequencies can make one assume that in spite of the severity of the offense, most cases involving juvenile offenders will be diverted to TYC instead of adult courts. 
Table 2. Severity of Offense

\begin{tabular}{|c|c|c|c|c|}
\hline \multirow{2}{*}{$\begin{array}{l}\text { Race/ethnicity } \\
\text { Percent }\end{array}$} & sex/gender & & & Frequency \\
\hline & Female & state jail felony & & 783 \\
\hline \multicolumn{5}{|l|}{54.9} \\
\hline & & $3 r d$ & degree & felony \\
\hline \multirow[t]{2}{*}{225} & 15.8 & & & \\
\hline & & $2 n d$ & degree & felony \\
\hline \multirow[t]{2}{*}{345} & 24.2 & & & \\
\hline & & $1 \mathrm{st}$ & degree & felony \\
\hline \multirow[t]{2}{*}{70} & 4.9 & & & \\
\hline & & felony & (not & specified) \\
\hline \multirow[t]{2}{*}{4} & .3 & & & \\
\hline & & Total & & \\
\hline \multirow[t]{2}{*}{1474} & 100.0 & & & \\
\hline & Male & & state & felony \\
\hline \multirow[t]{2}{*}{2843} & 44.8 & & & \\
\hline & & $3 \mathrm{rd}$ & degree & felony \\
\hline \multirow[t]{2}{*}{800} & 12.6 & & & \\
\hline & & 2nd & degree & felony \\
\hline \multirow[t]{2}{*}{2167} & 34.1 & & & \\
\hline & & $1 \mathrm{st}$ & degree & felony \\
\hline \multirow[t]{2}{*}{538} & 8.5 & & & \\
\hline & & felony & (not & specified) \\
\hline \multirow[t]{2}{*}{3} & .0 & & & \\
\hline & & Total & & \\
\hline 6351 & 100.0 & & & \\
\hline
\end{tabular}

African American Female

state jail felony

34.7

176

317

40

816
21.6

38.8

4.9

3rd degree felony

2nd degree felony

1st degree felony

Total

Male

state jail felony

2049

45.2

3rd degree felony 
1444

504

4

816

Hispanic 49.7

234

303

43

4

1160

929

2475 34.6

588

14

7143

Asian

55.6

3

4

1

Male

43.9

Female
Female

state jail felony

31.8

11.1

2nd degree felony

1st degree felony

felony (not specified)

.1

Total

100.0

20.2

26.1

1st degree felony

felony (not specified)

.3

Total

13.0

state jail felony

3rd degree felony

2nd degree felony

1st degree felony

8.2

felony (not specified)

.2

Total

100.0

state jail felony

10

3rd degree felony

16.7

2nd degree felony

22.2

1st degree felony

5.6 
100

45

14

33

8

100
Male

45.0

14.0

33.0

8.0

100.0

American Indian Female 3.3

3

2

1

9

11

3

10

24

33.3

16.7

45.8

22.2

5.6

11.1

state jail felony

Male

Other Female

41.7

100.0

Total

state jail felony

3rd

degree felony

2nd degree felony

1st degree felony

Total

3

state jail felony

2

state jail felony

3rd degree felony

2nd degree felony

Total

Total 
12

7

14

3

36

Unknown

50.0

50.0
Male

33.3

19.4

38.9

8.3

100.0 state jail felony

3rd degree felony

2nd degree felony

1st degree felony

Total

3rd degree felony

1

2nd degree felony

Total

100.0

Table 2 examines race and gender as it pertains to the number of minorities committing felonies. According to Texas statute 1, State jail felony offenders receive a term in the state jail for no more than two years and less than 180 days; 2). Third degree felony offenders receive not more than two years less than ten in the institutional division of the department of corrections; 3). Second degree felony offenders receive terms of not more than 20 years but less than two years in the institutional division of the department of corrections; 4). First degree felony offenders receive no more than 99 years not less than five in the institutional division of the department of corrections. The figures in the table reveal high numbers of white females $(54 \%, n=1427)$ committed to state jails whereas African American female (34.7, $\mathrm{n}=816)$ receive the same disposition. Hispanic females $(49.7 \%, \mathrm{n}=1160)$, Asian $(55 \%$, $\mathrm{n}=18)$ and American Indian $(33.3 \%, \mathrm{n}=9)$ females received the same dispositions respectively. The primary focus of this particular study is the reductions of overwhelming numbers of minorities confined yet white women are confined at a rate that surpasses women who are nonwhite.

This study examined both crosstabulations and regression from table 3 of the study to determine whether age, race/ethnicity, sex, and severity have a positive or negative relationship pertaining to case disposition (TYC or Jail). Table will provide and explanation of the relationships that have a bearing on case disposition. The table below will provide the pertinent percentages as well as the symmetric measures needed to analyze the Spearman correlation the direction of the positive or negative relationships. 
Table 3. Crosstabulations

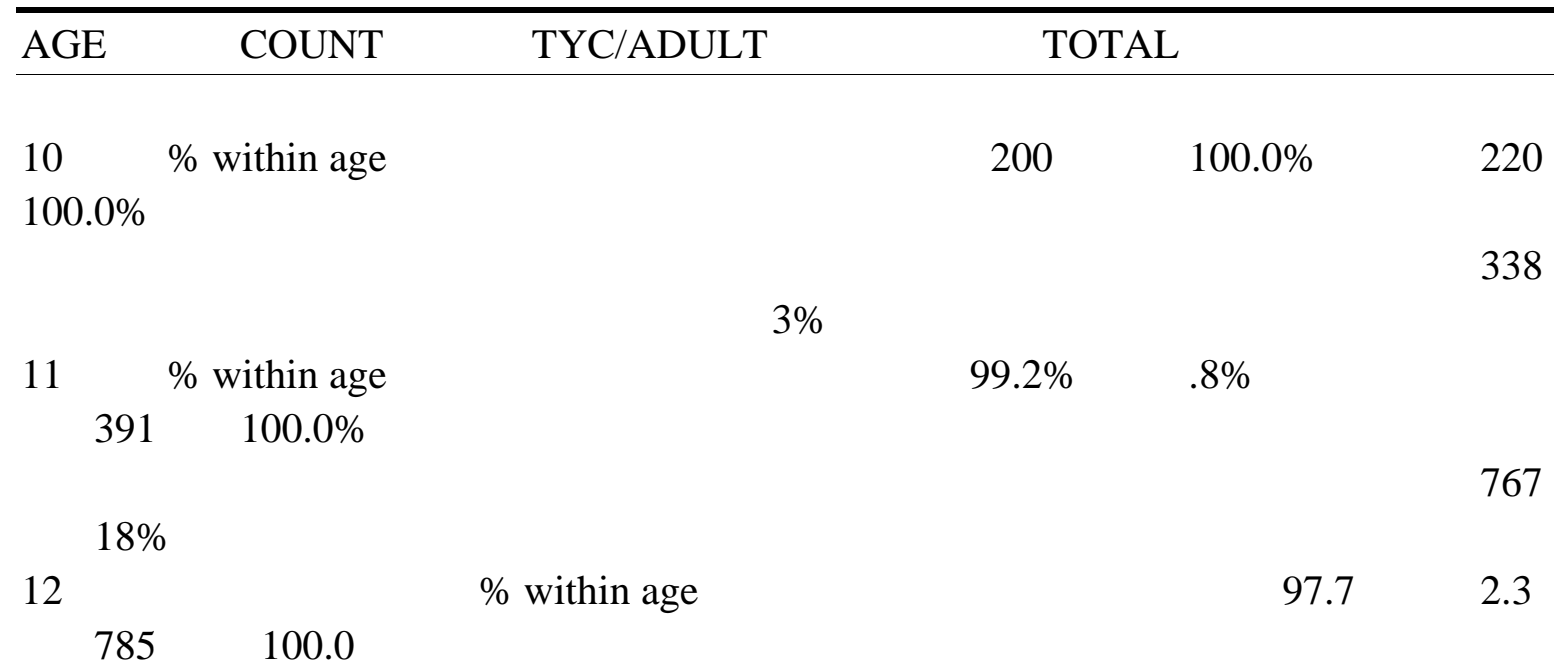

47

13

$\%$ within age

96.8

$1474 \quad 100.0$

141

14

$\%$ within age

93.8

6.2

$2278 \quad 100.0$

15

$\%$ within age

236

$2715 \quad 100.0$

2639

398

$16 \%$ within age

86.9

13.1

$3037 \quad 100.0$

138

21

$\begin{array}{lll}17 & & \% \text { within age }\end{array}$

86.8

13.2

Total

10195

864

\begin{tabular}{|c|c|c|c|c|}
\hline Age & $\%$ within & & 92.2 & .8 \\
\hline 3905 & 100.0 & & & \\
\hline Race & White & & 3682 & 223 \\
\hline & $\%$ within & & 94.30 & 5.70 \\
\hline & 3905 & 100.0 & & \\
\hline & Minority & & 6513 & \\
\hline
\end{tabular}




\section{$\%$ within \\ $\begin{array}{ll}7154 & 100.0\end{array}$}

91.00

Total

10195

864

Race/Ethnicity \% within

$92.20 \quad 7.80$

Male

8569

$9378 \quad 100.0$

$\%$ within

91.4

5.7

Female

1626

55

$\begin{array}{ll}7154 & 100.0\end{array}$

$\%$ within

96.7

3.3

Total

864

11059100.0

10192

Sex

$\%$ within

92.2

7.8

The case summary had no missing values relating to the independent variables age, race/ethnicity, sex, and severity in relationship to the dependent variable TYC or adult court. Table 1 reveals the row percentages of the independent variables age, race/ethnicity, sex, and severity. According to the data output, juveniles ages 10 have a $100 \%$ chance of going to TYC than being transferred to adult court regardless of the severity of offense.

Juveniles in the age categories 11- 15 are also more likely to be disposed to TYC according to the percentages respectively $(11=99.2 \% ; 12=97.7 \% ; 13=96.8 \% ; 14=93.8 \% ; 15=$ 91.3\%). Although the chances of going to TYC among the aforementioned age group is high, there still were instances where the few juveniles had cases diverted to adult court $(11=.8 \%$; $12=2.3 ; 13=3.2 \% ; 14=6.2 \% ; 15=8.7 \%)$. Juveniles ages 16 and 17 also have a greater chance of being sentenced to TYC but $13 \%$ of youths within this particular age group had a chance of their cases being diverted to the adult court.

With regards to race, $94 \%$ were likely to be diverted to probation or other types of rehabilitative measure. Five percent $(5.70 \%)$ white youths were more likely to be sent to TYC despite the sample size $(n=3682)$. Minority youths had a $91.4 \%$ chance of receiving probation or other forms of treatment to TYC due to their sample size (6513) however while the percentage may be small, $9.0 \%$ had chances of being diverted to adult court as compared to their white counterparts. An analysis of gender/sex shows that those cases whether TYC or adult comprised of male subjects $(n=8569)$ whereas $96.7 \%$ were female yet the data shows a relatively small population of females $(n=1626)$. Examination demographics variables of reveals that $5.7 \%$ of the males in the study were sent to TYC or transferred to the adult courts while 3.3 percent of females were diverted to TYC or adult court. Males are more likely to commit offenses than females.

The offenses within the data set relied on felonies primarily to determine if severity of offense played a role in determining who goes to TYC or are processed to the adult courts. Felonies were broken down by degree, with third degree being the most serious and first degree the least serious. $94 \%$ of the felonies committed were second degree felonies 


\section{Macrothink}

$(n=6348) ; 79.3 \% \quad(n=1359)$ of individuals committed the most serious of felonies serious felonies yet 20.7 or one fifth of those offenders cases were transferred to the adult court. Juveniles committed $94.4 \%$ of second degree felonies yet 377 of those cases were sent to the adult courts. Juveniles that committed second degree felonies were referred to the adult court more often than those who commit 3rd and 1st degree felonies.

\section{Symmetric Measures}

Correlational Analysis will provide the correlations with regard to Spearman correlation and Pearson's R because the study examines the relationship that the correlates age, race/ethnicity, sex, and severity and how it affects TYC or adult court diversions. Most useful method of analysis for this study is the symmetric measures. Within all categories there was significance with regards to age, race/ethnicity, sex, and severity. Isolating but not eliminating age to dependent variable TYC or jail yielded a positive association $(\mathrm{t}=15.711$; sig<.000) suggests that age is positively significant in determining who goes to TYC or adult court. 1

Race/Ethnicity, sex, and severity showed similar results to the dependent variable. Race indicators show a positive correlation $(\mathrm{t}=6.095$; $\mathrm{sig}<.000)$ in determining the outcome of dispositions. On the other hand, sex/gender and severity reveal a significant relationship in determining diversion to TYC or adult court ( $\mathrm{sex}, \mathrm{t}=-7.552 ;<.000$ ); ( meaning that there is a strong possibility of diversion despite severity relationship in certainty of who receives TYC or an adult court judgment.

Table 4 seeks dependence of multiple ordinal variables on predictor variables namely age, race, sex, and severity on TYC or adult court. A careful examination reveals negative confidence intervals from ages 10-15. One could assume that the younger an individual is the more likely they would be diverted from TYC or adult court. Sex and severity assumes a more positive relationship meaning that these variables are reliable in predicting more diversion than disposition to TYC or adult court. The analysis of age, sex, race/ ethnicity, and severity as compared to TYC or adult court was a correlational analysis. Ages ranged from 10-17 years old according to a data set obtained from the Texas Juvenile Crime Prevention Center. 
Table 4. Multiple Ordinal Variables Regression

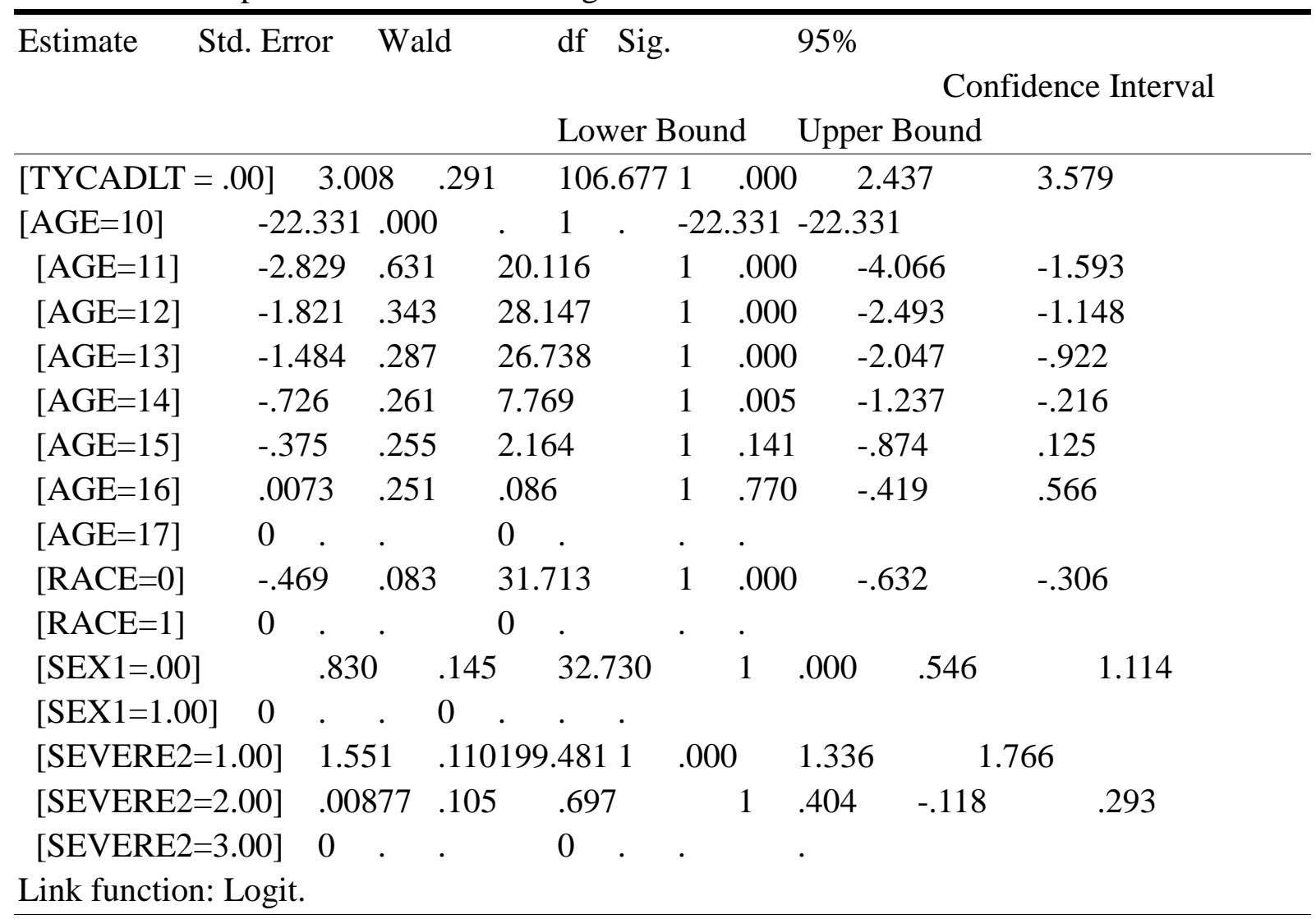

a. This parameter is set to zero because it is redundant.

The data was extrapolated from a data set containing relevant information using gathered during 2001 using the Casework research program. The larger data set used was condensed due to the nature of its size; therefore, it was reduced to examine 11059 cases due to time constraints and manageability. Sex, race, and severity had to be recoded to reduce the number of missing cases to allow for more reliable and accurate findings. Disproportionate Minority Confinement was investigated in response to the federal government's acknowledgement that minority incarceration rates were exacerbating. The Congressional enactment of Title II part B formula grants was not a solution to the problem but a litmus test to determine if States with unusually high minority populations exercised fairness with regards to alternatives to juvenile incarceration or even worse transferring youths to adult courts. The primary goal of this study was to determine what factors were led to high rates of incarceration of minority populations.

\section{Conclusion}

The null hypothesis was age, sex, race, and severity were determinants in who gets confined to a youth facility or transferred to the adult court. The data revealed that Texas was proactive with diverting youth offenders to probation or other forms of diversion. The high percentages of youths being diverted from the system suggest that the hypothesis should be rejected. The researcher had taken all factors into consideration to see if either variable had a bearing on disposition yet age, sex, race/ ethnicity, and severity had little bearing on disposition. The 


\section{Macrothink}

Journal of Sociological Research

ISSN 1948-5468 2015, Vol. 6, No.1

Spearman's correlations revealed that in spite of the variables studied in relation to disposition juveniles, minority and non-minority were diverted away from TYC or adult court.

The limitations to the research were due primarily with the data set. Problems with the data set narrowed the research in terms of offenses committed and other relevant factors. Felonies were examined without taking into account of misdemeanors. Data had to be untangled and recoded to provide the most accurate findings. Most importantly, areas impacted by disproportionate minority confinement could not be studied due to gaps in the data set. Variables that were manageable were used due to its complete nature. 


\section{Macrothink}

Journal of Sociological Research

ISSN 1948-5468

2015, Vol. 6, No.1

\section{References}

Balkan, S., R. Berger, and J. Schmidt.1980. Crime and Deviance in America: A Critical Approach. Belmont, Calif.: Wadsworth.

Bilchik, S. 1990. "Minorities in the Juvenile Justice System.” 1999 National Report Series. Paper prepared by the Office of Juvenile Justice and Delinquency Prevention.

Bishop, D. and C. Frazier. 1988. "The Influence of Race in Juvenile Justice Processing." Journal of Research in Crime and Delinquency 25:242-63.

Dahrendorf, R. 1958. "Out of Utopia: Toward a Reconstruction of Sociological Analysis." American Journal of Sociology. 67: 115-127.

Engen, R.L., Steen, S. \& Bridges, G.S. 2002. Racial Disparities in the punishment of youth: A theoretical and empirical assessment of the literature. Social Problems, 49 (2), 194-220.

Leiber, M. and J. Stairs. 1999. "Race, Contexts, and Use of Intake Diversion." Journal of Research in Crime and Delinquency 36: 56-86.

Lotke, E. and V. Schiraldi. 2005. "Juvenile Detention Alternatives Initiative." Paper prepared by A project of the Building Blocks for Youth Initiative.

Pope, C., Lovell, R., Hsia, H. 2002. Disproportionate minority confinement: A review of the research literature from 1989 through 2001. Washington, DC. Office of Juvenile Justice and Delinquency Prevention.

Rodney, H. E. and H. R. Tachia. 2004. Over-representation of Minorities in the Juvenile Justice System: Three Counties in Rural Texas. Federal Probation 68: 43-47.

Rodney, H. E., H. R. Tachia, and N. Walters. 2004. Factors Influencing the Disposition Phase Decisions in the Juvenile Justice System. Texas Probation. 19: 9-12.

Sorenson, J., R. Hope, and D. Stemen. 2003. Racial disproportionality in state prison admissions: Can regional variation be explained by differential arrest rates? Journal of Criminal Justice 31: 73-84.

Texas Juvenile Crime Prevention Center. 2001. Data set (Casework software). 